\title{
Deutschland als wirtschaftspolitischer Lehr- und Zucht- meister Europas - eine gefährliche Selbstüberschätzung
}

\author{
ACHIM TRUGER
}

$E$

ine weitverbreitete Haltung hierzulande lautet in etwa so: Deutschland ist der wirtschaftspolitische Vorreiter in Europa. Während fast alle anderen in der Krise versinken, ist die deutsche Wirtschaft im Aufschwung. Die Arbeitslosigkeit schrumpft und die Haushaltskonsolidierung kommt voran. Der wesentliche Grund für die Erfolge: Die Deutschen haben ihre „Hausaufgaben" frühzeitig gemacht. Durch Agenda 2010 und harte Sparpolitik mussten sie zwar eine Durststrecke auf sich nehmen, doch nun zahle sich der mutige Reformwille aus.

Daraus leitet sich für viele auch die Legitimation Deutschlands als Lehr- und Zuchtmeister für die Krisenstaaten im Euroraum ab, denen nun anscheinend mit gutem Recht Ähnliches abverlangt wird. Zwar bedauern einige die Leiden der Menschen dort, allerdings seien sie angesichts der vorherigen Verfehlungen unvermeidbar. Ein stärkeres Engagement Deutschlands in der Eurokrise sei dagegen nicht zu verantworten, weil man damit gleichsam den Musterschüler für das Fehlverhalten der Sitzenbleiber bestrafen würde. Obwohl diese Haltung charakteristisch für die bisherige deutsche Krisenpolitik ist, beruht sie auf gravierenden Fehleinschätzungen.

Nicht richtig ist, erstens, schon die positive Einschätzung der Lage in Deutschland: Zwar steht die deutsche Wirtschaft relativ zu den europäischen Partnerländern sehr gut da. Auch hat sich die Lage seit den Stagnationsjahren 2001 bis 2005 stark verbessert. Dennoch stagnierte die Wirtschaftsleistung auch hierzulande de facto fast zwei Jahre lang vom 2. Quartal 2011 bis zum 1. Quartal 2013. Die Arbeitslosigkeit nahm zuletzt wieder leicht zu. Zudem ist die soziale Lage bei weiterhin knapp 3 Mio. Arbeitslosen, mehr als 7 Mio. Beschäftigten in Niedriglohnjobs und einer stark gestiegenen Einkommens- und Vermögensungleichheit alles andere als mustergültig.

Zweitens wird die brutale Austeritätspolitik in vielen Euroländern verharmlost. Den Staaten wurden in wenigen Jahren Ausgabenkürzungen und Abgabenerhöhungen von über $10 \%$ des Bruttoinlandsproduktes abverlangt. Das hat es hierzulande zuletzt in der Weimarer Republik unter Reichskanzler Brüning gegeben. Auf deutsche Verhältnisse übertragen wären es $270 \mathrm{Mrd}$. $€$, was $45 \%$ des gesamten deutschen Steueraufkommens oder knapp $90 \%$ des Bundeshaushalts entspräche. Kein Wunder, dass die betroffenen Staaten in einer Dauerrezession mit unerträglicher Massenarbeitslosigkeit und katastrophalen sozialen und politischen Verwerfungen gefangen sind.

Drittens ignoriert die gängige Erklärung für die relativ positive Entwicklung in Deutschland die zentralen makroökonomischen Ursachen: Die deutsche Wirtschaft wies während der schlechten Jahre keineswegs überdurchschnittlich „verkrustete“ Arbeitsmärkte auf, sondern wurde durch eine ungewöhnlich schwache Binnennachfrage aufgrund relativ hoher Realzinsen, einer ausgabenseitig restriktiven Finanzpolitik und einer extrem schwachen Lohnentwicklung ausgebremst. Der Aufschwung gelang erst, als die Finanzpolitik gelockert wurde und sich die starken außenwirtschaftlichen Impulse auf die Binnenwirtschaft übertragen konnten. Die große Krise im Jahr 2009 wurde vor allem aufgrund von Kurzarbeit und flexiblen Arbeitszeitkonten so schnell überwunden: Durch sie wurde der Einbruch in der Exportindustrie ohne Massenentlassungen überbrückt, bis die Exporte wieder ansprangen. Die Konjunkturpakete halfen, den Konsum zu stabilisieren, und sie verstärkten und verlängerten bis ins Jahr 2011 hinein auch durch höhere öffentliche Investitionen den Aufschwung. Neben dem günstigen Zufall einer für die deutsche Wirtschaft extrem gut zu bewältigenden Krise in den tarifpolitisch gut organisierten Branchen trug also auch die Wirtschaftspolitik zum Erfolg bei - über die Förderung der Kurzarbeit und die Konjunkturpakete. Es handelte sich aber gerade nicht um "Strukturreformen", sondern um eine antizyklische makroökonomische Politik. Und es ist gerade eine solche Politik, die den Krisenstaaten seit 2010 vor allem vonseiten der deutschen Regierung verwehrt wird.

Seither hat Deutschland schlicht großes Glück gehabt: Niedrige Realzinsen, eine aufgrund der günstigen Einnahmenentwicklung trotz Schuldenbremse wenig restriktive Fiskalpolitik und anziehende Löhne bei gleichzeitig günstiger Auslandskonjunktur haben die deutsche Wirtschaft vor dem Absturz bewahrt. Doch das muss nicht so bleiben: Geriete die deutsche Wirtschaft etwa aufgrund einer Verschärfung der Eurokrise, eines Einbruchs außerhalb Europas oder einer Krise der Automobilwirtschaft in einen kräftigen Abschwung, könnte es schnell vorbei sein mit der deutschen Herrlichkeit. Deutschland müsste den Abschwung wahrscheinlich im selbst geschnürten Zwangskorsett aus Schuldenbremse und Fiskalpakt empfindlich verschärfen und könnte in eine tiefe Krise stürzen.

Von den europäischen Partnern dürfte man dann wohl kaum auf Mitleid oder Unterstützung hoffen. Es ist Zeit, die deutsche Haltung in der Krisenpolitik zu überdenken.

ACHIM TRUGER ist Professor für Volkswirtschaftslehre an der Hochschule für Wirtschaft und Recht (HWR) Berlin. Arbeitsschwerpunkte: Makroökonomie und Wirtschaftspolitik, Steuer- und Finanzpolitik.

achim.truger@hwr-berlin.de 